\title{
KLIPPEL TRENAUNAY SYNDROME: A CASE REPORT
}

\section{Sonali Suman ${ }^{1}$, Ashutosh Kumar Sinha ${ }^{2}$, Smita Kumari ${ }^{3}$, Banani Sengupta ${ }^{4}$, Shreemant Gautam ${ }^{5}$}

\section{HOW TO CITE THIS ARTICLE:}

Sonali Suman, Ashutosh Kumar Sinha, Smita Kumari, Banani Sengupta, Shreemant Gautam. "Klippel Trenaunay Syndrome: A Case Report". Journal of Evolution of Medical and Dental Sciences 2015; Vol. 4, Issue 34, April 27; Page: 5981-5985, DOI: 10.14260/jemds/2015/871

ABSTRACT: INTRODUCTION: Klippel Trenaunay Syndrome is a rare congenital disorder, but it is the most common condition involving combined vascular malformation. KTS was first described by two French Physicians, Klippel and Trenaunay in 1900.(1) Incidence of KTS reported is approximately 2 to 5 cases per 100, 000 live births.(2,3) KTS generally affects a single extremity, although cases of multiple affected limbs have been reported. The leg is most common site followed by the arms, the trunk, and rarely the head and neck. The original description of KTS included limb hypertrophy, varicose veins and vascular (Port wine) nevus, which were characterised as a clinical triad. Hemangiomatosis is the most frequent finding in these patients and is usually present at birth.(4) KTS is also known as angio osteohypertrophy syndrome, congenital dysplastic angiopathy or klippel trenaunay weber syndrome. KEYWORDS: Klippel trenaunay syndrome (KTS), vascular malformation, soft tissue hypertrophy, venous varicosity.

CASE REPORT: A four year old female child presented to our OPD with complaints of progressive swelling of whole of right lower limb since birth. Swelling was present since birth and has slowly progressed to present size. She had no history of tuberculosis, fever with chills and rigor, trauma, and any other bleeding manifestation.

On examination, the patient was afebrile, moderate pallor was present. No clubbing, cyanosis or lymphadenopathy was present. Heart rate $=110 \mathrm{bpm}$, blood pressure $=96 / 60 \mathrm{mmHg}$, respiratory rate $=20 /$ min. Cardiopulmonary examination was unremarkable except tachycardia. Patient was cooperative but was little shy. All milestones were normal for age. No history of similar complaints in siblings. She had marked hypertrophy of her right lower limb. Her right calf and thigh were swollen and non-tender. Superficial varicose veins were palpated over her right calf muscles. No discrepancy in length was noted in two lower extremities. Slight pigmentation was noted near the tortuous veins, however no venous ulcers were present.

On lab investigations, her hemoglobin was 7.6gm\%, PBS- microcytic hypochromic anemia was present. Bleeding time, clotting time, prothrombin time, activated partial thromboplastin time were all normal. LFT and RFT were all normal. Chest x-ray and ECG were normal. Plain X-ray of the right hip and right leg revealed hypertrophy of soft tissues and bones. USG abdomen showed no organomegaly. Colour doppler of right lower limb demonstrated significant reflux at saphenofemoral junction. Superficial veins showed increased flow. Deep venous system was not present in right lower extremity. But in the left lower extremity superficial and deep venous system were normal. Echocardigraphy was done to rule out any possibility of cardiac overload, failure or any associated heart defects. However, echocardiography revealed no significant abnormality. Due to financial constraints chromosomal analysis was not done in this patient. The patient is now on regular follow up.

DISCUSSION: This case is a variant of KT Syndrome. KTS is a rare congenital malformation characterised by the triad of capillary malformation, venous malformation and bone or soft tissue 
hypertrophy. The most frequent clinical aspect of KTS is a dermal capillary stain associated with dilated marginal vein of Servelle often identified in the subcutaneous fat of the lateral calf and thigh. The capillary malformation, venous varicosities and limb hypertrophy has been found to occur in 98\%, 72\% and $67 \%$ of children with KTS respectively (Jacob et al).(5) It should be distinguished from Parkes weber syndrome by absence of underlying atriovenous malformation. Prominent superficial varicose veins are present in majority of patients.(6) Extremity pain, spontaneous hemorrhages, venous insufficiency or thrombophlebitis are commonly encountered.(6)

The cause of KTS remains unclear, however many workers believe it to be caused by mesodermal abnormality during fetal development leading to vascular and soft tissue malformations in the affected limb (Baskerville et al, 1985).(7) The de novo translocation $t(8 ; 14)$ (q22. 3:q13) has also been reported (Wang et al, 2001).(8) Most cases of KTS are sporadic. But there are certain cases reported which suggests an autosomal dominant pattern of inheritance.(9) Happle (1993) suggested a paradominant inheritance, caused by single gene defect. The trait is only expressed when a somatic mutation occurs in the normal allele at an early stage of embryogenesis, giving rise to a clonal proliferation of cells either homozygous or hemizygous for KTS mutation.(10)

Ultrasonography, Doppler study, contrast enhanced MRI, Venogram are required for definitive diagnosis of KTS. Management of KTS is dependent upon individual symptoms. Although both non operative and surgical approaches are used, management is mainly supportive and symptomatic. Compressive garments are advised for chronic venous insufficiency, lymphedema, recurrent cellulitis and recurrent bleeding from the capillary or venous malformation. Pain medication, antibiotics and limb elevation are all used to manage cellulitis. Many studies have given positive results in patients using compression therapy (Stringel and Dastous, 1987). Laser therapy indicated when there is ulceration and breakdown of lymphatic blebs. Surgery includes vein ligation, vein resection and in rare cases, removal of problematic area of abnormal tissue (debunking surgery) and amputation. Rapamycin has also shown to improve quality of life in these patients by improving pain, decreasing bleeding from lymphatic blebs.

Fig. 1: Doppler image demonstrating significance reflux at sapheno-femoral junction.

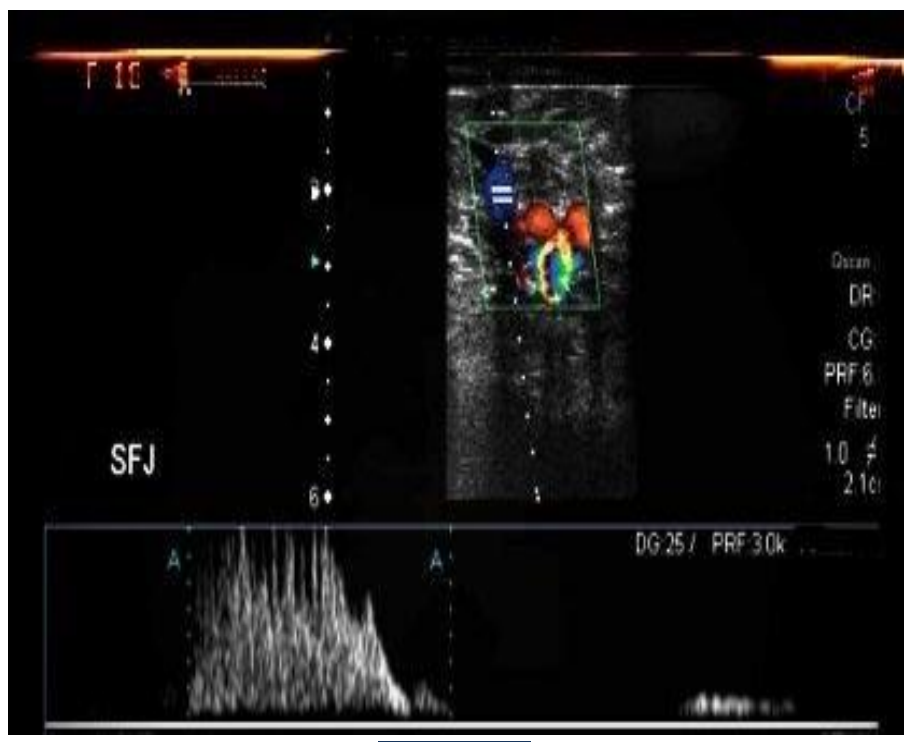

Fig. 1 


\section{CASE REPORT}

Fig. 2: Colour Doppler showing absent deep venous system.

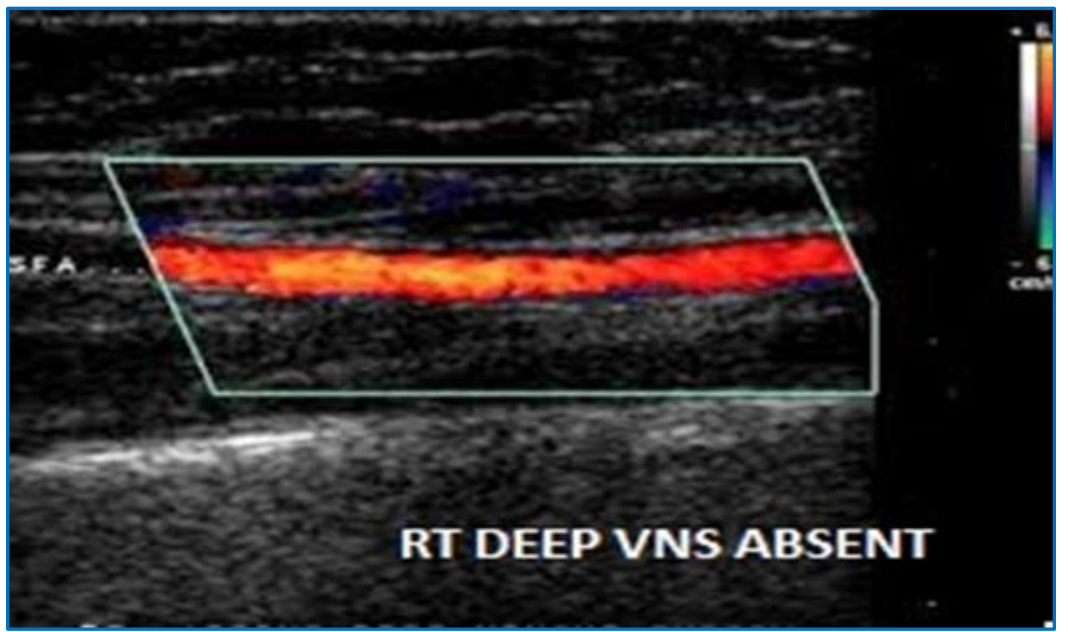

Fig. 2

Fig. 3: Doppler image showing continuous reflux in sapheno-femoral junction.

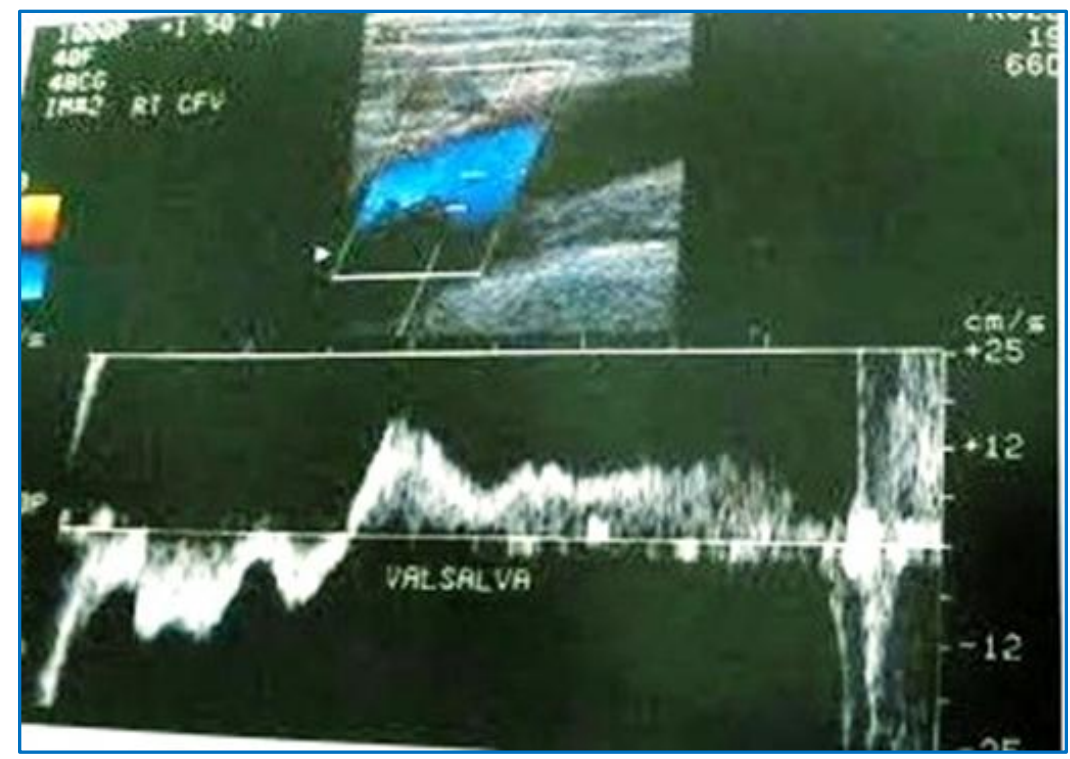

Fig. 3 


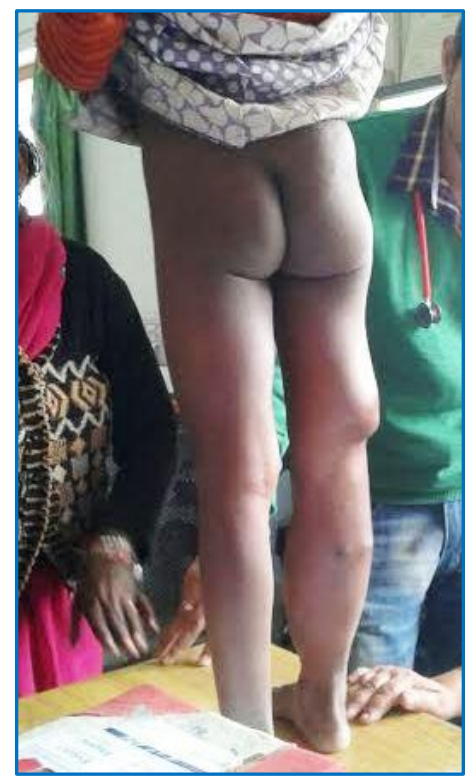

Fig. 4

\section{REFERENCES:}

1. Klippel M, Trénaunay P. Du Noevus variquex osteohypertrophiques. Arch of Gen Med (Paris) 1900; 3: 641-72.

2. Atherton DJ. Naevi and other developmental defects. Vascular naevi. In: Champion RH, Burton.JL, Burns DA, Breathnac SM, Eds. Textbook of Dermatology. 6th Ed. London: Oxford Blackwell Scientific Publications; 1998: 585-8.

3. Suchitra G, Madhu R, Srinivasan MS. Klippel Trenaunay syndrome. E J Indian Soc Teledermatol. 2008; 2(4):7-14.

4. Gorlin RJ, Pindborg JJ: Syndromes of the head and neck, 2nd ED. NEW YORK: McGraw Hill Book Co, 1976. 412-17.

5. Jacob AG, Driscoll DJ, Shaughnessy WJ, Stanson AW, Clay RP, Gloviczki P. Klippel -Tre'naunay syndrome: spectrum and management. Mayo Clin Proc 1998; 73: 28e36.

6. Gloviczki P et al (1991) Klippel - Trenaunay syndrome: the risk and benefits of vascular interventions surgery 110: 469-79.

7. Baskerville PA, Ackroyd JS, Browse NL: The etiology of The Klippel- Trenaunay syndrome. Annals of Surgery, 1985; 202 (5): 624-627.

8. Hu Y, Li L, Seidelmann SB, Timur AA, Shen PH, Driscoll DJ, Wang QK: Identification of association of common AGGF1 variants with susceptibility for Klippel Trenaunay syndrome using the structure association program. Annals of Human Genetics, 2008; 72 (5): 636- 643.

9. Ceballos -Quintal JM, Pinto - Escalante D, A New Case of Klippel Trenaunay Weber Syndromeevidence of autosomal dominant inheritance Am. J Med Genet, Jun 14 1996, 63(5): 426 (7).

10. Happle R: Klippel- Trenaunay syndrome: Is it a Paradominant trait? British Journal of Dermatology, 1993; 128 (4): 465. 


\section{CASE REPORT}

\section{AUTHORS:}

1. Sonali Suman

2. Ashutosh Kumar Sinha

3. Smita Kumari

4. Banani Sengupta

5. Shreemant Gautam

\section{PARTICULARS OF CONTRIBUTORS:}

1. Post Graduate Resident, Department of Pediatrics, MGM Medical College, Kishanganj.

2. Consultant Cardiologist, Department of Cardiology, SMIMS, Sikkim.

3. Consultant Gynaecologist, Department of Gynaecology, MGM Hospital, Patna.

FINANCIAL OR OTHER

COMPETING INTERESTS: None
4. Professor \& HOD, Department of Pediatrics. MGM Medical College, Kishanganj.

5. Post Graduate Resident, Department of Pediatrics, MGM Medical College, Kishanganj.

\section{NAME ADDRESS EMAIL ID OF THE CORRESPONDING AUTHOR:}

Dr. Sonali Suman,

Nalanda Scan Centre, 0/63, Doctors Colony, Kankerbagh, Patna-800020, Bihar.

E-mail: sonali.suman@gmail.com

Date of Submission: 30/03/2015.

Date of Peer Review: 31/03/2015.

Date of Acceptance: 16/04/2015.

Date of Publishing: 27/04/2015. 